\title{
Article
}

\section{Challenges for Agriculture through Industry 4.0}

\author{
Heinz Bernhardt 1,*(D), Mehmet Bozkurt ${ }^{2}$, Reiner Brunsch ${ }^{3}$, Eduardo Colangelo ${ }^{4}$, Andreas Herrmann ${ }^{2}$, \\ Jan Horstmann ${ }^{5}$, Martin Kraft ${ }^{6}$, Johannes Marquering ${ }^{7}$, Thilo Steckel ${ }^{8}$, Heiko Tapken ${ }^{9}$, Cornelia Weltzien ${ }^{3}$ and \\ Clemens Westerkamp 9
}

check for updates

Citation: Bernhardt, H.; Bozkurt, M.; Brunsch, R.; Colangelo, E.; Herrmann, A.; Horstmann, J.; Kraft, M.; Marquering, J.; Steckel, T.; Tapken, H.; et al. Challenges for Agriculture through Industry 4.0. Agronomy 2021, 11, 1935. https://doi.org/10.3390/ agronomy11101935

Academic Editors: Fátima Baptista, Luis Leopoldo Silva, José

Carlos Barbosa, Vasco Fitas da Cruz, Adélia Sousa, José Rafael Silva and Patrícia Lourenço

Received: 12 August 2021

Accepted: 22 September 2021

Published: 27 September 2021

Publisher's Note: MDPI stays neutral with regard to jurisdictional claims in published maps and institutional affiliations.

Copyright: (c) 2021 by the authors. Licensee MDPI, Basel, Switzerland. This article is an open access article distributed under the terms and conditions of the Creative Commons Attribution (CC BY) license (https:/ / creativecommons.org/licenses/by/ $4.0 /)$.
1 Agricultural System Engineering, Technical University of Munich, 85354 Freising, Germany

2 VDI-The Association of German Engineers, 40468 Düsseldorf, Germany; Bozkurt@vdi.de (M.B.); herrmann@vdi.de (A.H.)

3 ATB Leibniz-Institut für Agrartechnik und Bioökonomie, 14469 Potsdam, Germany; rbrunsch@atb-potsdam.de (R.B.); CWeltzien@atb-potsdam.de (C.W.)

4 Fraunhofer IPA, 70569 Stuttgart, Germany; eduardo.colangelo@ipa.fraunhofer.de

5 Maschinenfabrik Bernard KRONE GmbH \& Co., KG, 48480 Spelle, Germany; Jan.horstmann@krone.de

6 Johann Heinrich von Thuenen Institute, Institute of Agricultural Technology, 38116 Braunschweig, Germany; martin.kraft@thuenen.de

7 Department of Engineering Sciences, University of Applied Sciences Jade, 26389 Wilhelmshaven, Germany; johannes.marquering@jade-hs.de

8 CLAAS E-Systems GmbH, 49201 Dissen, Germany; thilo.steckel@claas.com

9 Faculty of Engineering and Computer Science, University of Applied Sciences Osnabrueck, 49076 Osnabrueck, Germany; h.tapken@hs-osnabrueck.de (H.T.); c.westerkamp@hs-osnabrueck.de (C.W.)

* Correspondence: heinz.bernhardt@wzw.tum.de; Tel.: +49-8161-713086

Abstract: Industry 4.0 is currently considered the structural implementation of networked and cooperative digitalisation and the next step in technological and social development. The aim of this paper is to examine how these structures are also suitable for agriculture and whether there are already approaches to this. Therefore, the main aspects of Industry 4.0 will be analysed and compared with agricultural examples from arable farming and livestock farming. The study shows that the approaches of Industry 4.0 are also useful for agriculture. However, they must be adapted to agriculture, as it has a different basic structure. As in industry, it is also evident in agriculture that there is still a need for action in the organisational and technical networking of systems.

Keywords: agriculture 4.0; digitization; networks; data communication; smart farming

\section{Introduction}

The terms Industry 4.0 and Agriculture 4.0 are currently the subject of much public debate concerning the future development of the sectors. However, a more detailed analysis shows that both the content of the individual terms and their possible interrelationships are not sufficiently clarified. In many cases, everyone associates them with his or her own image and imagination [1-4]. As a result, although everyone uses the same term, very different ideas are associated with it. This is a very poor basis for a common orientation that the pair of terms is intended to achieve [5].

Here, a structure is to be created within the framework of a VDI/VDE guideline committee on the subject of "State of Industrial Use 4.0-Technologies in Agricultural Engineering". The discussion covers several levels. It is based on the current understanding of the term Industry 4.0 with its structure and objective for the industrial sector. In the transition from Industry 4.0 to agriculture, the sectoral differences between industry and agriculture must be analyzed. This includes not only technology, but also the different orientations in economics, ecology, and sociology. Based on this, the current state of Industry 4.0 technologies and concepts in agriculture will be presented in practice and theory using various examples from arable and livestock farming. In summary, it can be seen that the contents of the terms used still need to be coordinated in many areas [6]. 
The term "Agriculture 4.0" has developed from the term Industry 4.0 which in turn will be regarded later in this introduction. However, the term "Agriculture 4.0" is even more difficult to grasp than Industry 4.0. So far, "Agriculture 4.0" has been little more than a kind of advertising slogan, claiming state-of-the-art IT and production concepts and techniques for agriculture. Often, "Agriculture 4.0" is simply used in reference to digital techniques in agriculture and precision farming, as in Roland Berger Focus-Agriculture 4.0 [7]. In order to find a well-founded definition of "Agriculture 4.0" as a revolutionary stage of agricultural production, generations 1.0-3.0 of agriculture must first be defined. At first glance, it looks relatively easy to name the individual stages with threshing machine, tractor, and ISOBUS (ISO 11783) for machine communication. However, others also mention mineral fertilizer or the green revolution as corresponding stages. It is therefore relatively difficult to describe the revolution that led to 4.0 in agriculture, that is if there is a revolution at all that justifies a new generation. On the other hand, some authors already see a coming "Agriculture 5.0" on the horizon [8,9]. The discussion and definition of revolutionary stages of agricultural production is outside the scope of this paper, and the term "Agriculture 4.0" will be avoided. This paper focusses only on the aspects of Industry 4.0 in the agricultural domain.

The term "Industry 4.0" became widely known with the Hannover Fair in 2013. It goes back to an initiative of the Federal Government in Germany in 2011 [10]. To date, there is still no binding definition of the term "Industry 4.0", but a generally accepted understanding is emerging [11-13].

In order to check the transferability of Industry 4.0 applications to agriculture, it is first necessary to clarify how the system is understood in the industry. Over the last 270 years, industry has developed in the context of the so-called "industrial revolutions". The first industrial revolution began in the second half of the 18th century with the development of the steam engine. The second revolution took place towards the end of the 19th century with the development of mass production and the use of electrical energy. In the second half of the 20th century, the third industrial revolution began, characterized by the automation of production using electronic and IT approaches.

Each industrial revolution brings about a fundamental change in the production paradigm, made possible by the development of one or more technologies which trigger a fundamental change in established ideas and practices. However, their impact is not limited to production. Indeed, they extend to and influence the whole of society.

The current stage, caused by the fourth industrial revolution, is known as Industry 4.0. It differs from the third industrial revolution in that it focuses on networking the various automation modules [14].

Despite the current widespread referencing to the Industry 4.0 concept, it is difficult to find a clear definition. The term is best described by its fundamental prerequisites and its characteristic implementation options (Table 1).

Table 1. Key technologies and concepts of industry 4.0.

\begin{tabular}{ll}
\hline Category & Technology, Concept \\
\hline $\begin{array}{l}\text { Fundamental prerequisites of Industry 4.0 } \\
\text { ("Enabler") }\end{array}$ & - Internetworking \\
\hline & - Service orientation and interoperability \\
\hline & - Digital individualization ("lot size 1") \\
& - Flexibilisation \\
Implementation options of Industry 4.0 & - Demand orientation/ "X as a Service” \\
("Benefits") & - Sustainability \\
& - Process orientation \\
& - Collaboration competence \\
& - Productivity optimisation \\
\hline
\end{tabular}


From a purely technical point of view, Industry 4.0 approaches can be summarized under the term networking. Instead of managing different machines, sensors, etc., individually, as was previously the case, Industry 4.0 is based on cyber-physical systems (CPS), which can be connected and used flexibly, and on the equally flexible service-oriented architecture (SOA), which enables the use of the necessary software components [15]. This also improves the possibility of simulating processes up to the digital twin of the process. However, the networked and service-oriented character of Industry 4.0 goes beyond the boundaries of purely technical aspects and enables the design of new business models [16].

From this, the following implementation options [17] can be derived for the intelligent products and services to be offered by Industry 4.0:

Digital individualization: Digital media considerably simplify the offer of individualised products and services. This includes the entire production chain from customer request to realisation.

Flexibilisation: Industry 4.0 offers, for example, the possibility to react quickly to fluctuations in demand by making production capacities more easily scalable (e.g., through more intelligent plants and simplified capacity procurement) and by making more data available about the environment and the company itself.

Demand orientation/"X-as a service": Service orientation will be transferred to business models, which in turn will be facilitated by increasing data volume and flexibility. For example, products and services can be offered and billed according to the extent of use.

Sustainability: Better planning and control of production processes through digitisation can save resources, e.g., through cost- and load-optimised production programmes for energy-intensive processes. The availability of extended and timely data from production and the supply chain, e.g., through the early detection of quality problems, allows an additional reduction in resource requirements.

Consistent process orientation: The networking capability enables each value-added stage in the supply chain (internal and external to the company) to call up information on the overall process. This enables a customer- and employee-oriented work organisation.

Automated knowledge and learning: The increase in data volume and the degree of automation in Industry 4.0 environments prove to be ideal prerequisites for the use of self-learning functionalities. The data can come from outside the company boundaries, for example through IoT approaches. In addition, the systems in question enable extended and simplified knowledge management in companies.

Collaboration competence: In terms of end-to-end process optimisation, Industry 4.0 approaches reduce the necessary effort for cooperation between value-added partners. For example, it is possible to know the current stock and available capacity of suppliers.

Productivity optimisation: All the above-mentioned implementation options contribute to an increase in productivity. Optimisation options can be found at various levels, from the strategic orientation of the company to the operational management of production processes.

Although these implementation options have been analysed for the machinery and equipment sector, the identified benefits are also relevant for agriculture. However, implementing a highly flexible and distributed architecture is not without its challenges. The desired fast connection in the production chain also requires a corresponding data exchange. However, this requires appropriate standardisation or standardised interfaces and data formats between components from different manufacturers.

The processing and storage of data on distributed systems, often outside the company, gives cause for concern about data security. Both software-based and methodical approaches are being developed for this purpose. While the former are based on novel security applications and protocols, the latter focus on issues such as intelligent data control and anonymization. The analysis of the definition of Industry 4.0 shows that this definition is still under development and discussion.

If the definition of Industry 4.0 is applied to agriculture, it quickly becomes clear that agriculture is still characterised by additional aspects [18]. Particularly striking here is the 
environmental character of agriculture, which includes not only society and the state, but also to a large extent nature, the environment, people, farm animals, and the weather. The organisation of work is also structured differently in agriculture than in industry. This shows that the socio-economic, technical, and ecological systems in agriculture are much more closely interwoven, which makes the definition of "Agriculture 4.0" more difficult than in industry.

The aim of this paper is a short analysis of the applicability and the state of implementation of fundamental prerequisites and implementation options of Industry 4.0 (Table 1) in today's agriculture. Basic challenges to ease their integration into agricultural production will be identified.

\section{Materials and Methods}

In order to understand the current status of Industry 4.0 approaches in agricultural production, examples from arable farming and livestock farming were analyzed along the key technologies and concepts of Industry 4.0 (Table 1). These key parameters were selected and applied in order to clearly delimitate Industry 4.0 from general digitization and automation aspects.

For this purpose, different agricultural processes were described which, viewed from the outside, have a high level of technological development and can therefore be considered as future-oriented for current development. From the various analyses of the working group, grain harvesting with the subsequent logistics was selected as an example for arable farming and automation in animal husbandry as an example in the field of livestock farming. For the technologies and structures, the current state of farms in Germany and Central Europe was used.

Analysis of the three selected examples included aspects of automation and digitization, and the analysis regarded the difference of preconditions in industrial and agricultural production.

The analysis of the three examples was conducted in combination. After the finding that almost no "pure" Industry 4.0 technology has found implementation in the analyzed examples of agriculture so far, the role of possible obstacles was estimated. Those obstacles that can be overcome despite the basic difference between industrial and agricultural production preconditions were regarded further. From the examination of the individual agricultural processes, a cluster analysis was carried out to determine which topics are often considered difficulties. This identified the main challenges for the integration of Industry 4.0 technologies and concepts in agriculture.

\section{Results}

\subsection{Approaches for Industry 4.0 in Arable Farming \\ 3.1.1. Focus on Combine Harvesters}

Combine harvesters are among the most complex agricultural machines. Several hundred measurement and control variables have to be taken into account in order to achieve the desired result in the harvest. The combine harvester has the advantage that it is a single machine. It does not have to communicate with several machines for the process, as is the case with the tractor with soil cultivation and sowing. Assistance systems were used early on to manage the complexity in the combine. These control and regulation systems manage the threshing process. For example, the headers' speed is controlled according to the advance speed. The threshing cylinder is adjusted automatically according to grain type, machine utilisation, and cleaning quality. The subsequent cleaning stages are regulated according to cleaning quality and loss rate. Parallel travel systems with GNSS are used for logistics on the field. All process data are documented and analysed externally via data networks. This level of automation shows a certain similarity to industry, which simplifies the analysis with Industry 4.0 approaches.

There are limits to digital individualisation in numerous cultures and forms of exploitation. In the area of large crops, such as wheat, maize, and soya, it is important to 
realise the greatest possible mass flows while complying with certain limit values. Individualisation can be found in the areas of area planning, vehicle design, and straw processing. Methods for selective harvesting would be a good example of individualisation, although it has not yet become established.

For climatic reasons, there are narrow limits to the flexibility of harvesting in the open field. Greater flexibility can be achieved if it is possible to limit the variability of the environment, which is not necessarily in the spirit of sustainable agriculture, or to design the specificity of machines in such a way that they can follow the variability of the environment as well as possible.

The advent of sensors and corresponding telematics systems has led to a corresponding transparency of information in combine harvesters. The general availability of mobile devices contributes to the fact that these data are now also available to all participants at the same time.

The high investment volume and short service life associated with combine harvesters for individual farms have long led to service offers for harvesting capacities. In most cases, the entire harvest is contracted out on the basis of the harvested area. The offer of peak load capacities for fluctuating harvest volumes hardly exists. Increasing digitalisation could provide the basis for more precise recording and evaluation and enable new offers here.

The current state of harvesting technology has different impacts on sustainability. Currently, larger machines and increased efficiency save resources, but these larger machines can also lead to increased ground pressure.

Combine harvesters are already highly process-oriented. Currently, this is still associated with a high degree of internal complexity. Methods from the Industry 4.0 toolbox can improve this.

The high degree of digitalisation in combine harvesters already creates an extensive basis for generating and using automated knowledge and learning. This provides a good basis for the training of employees, as the operating time of the machine is limited and high performance must be achieved during this period.

Collaboration skills as well as productivity optimisation are a central point in the further development of the combine harvester. So far, the combine harvester has been optimised as an individual machine. To enable productivity increases in the future, interaction with other process participants such as logistics is necessary. This offers corresponding opportunities for Industry 4.0 applications.

The concept of services and interoperability in harvesting processes is complex. Harvesting as a mechanised process is offered as a service for the reasons already mentioned. Service engineering methods can be used to further develop such services into hybrid service bundles. Service platforms for trading harvesting capacities, offers for breaking peak loads, individualised billing modalities, and special data offers are examples of diverse possibilities.

\subsubsection{Focus on Logistics}

Almost all processes in agriculture contain logistical components. Nevertheless, little attention is paid to this area. Agriculture describes itself as a "transport industry against its will". This fact makes it particularly interesting with regard to Industry 4.0 aspects.

Unlike industrial logistics, logistical processes in agriculture do not run according to a timetable. Due to local conditions and boundary conditions that are difficult to plan, individualisation inevitably results. Digital individualisation in Industry 4.0 is an active measure, whereas in agriculture it is more of a reactive measure. In order to implement digital individualisation in agricultural logistics, it is necessary to apply complex methods due to the complex influencing factors.

Flexibility is a basic structure in agricultural logistics due to the multitude of product and process requirements. In contrast to industry, agriculture has never succeeded in standardising these, so the Industry 4.0 approach to flexibilisation is advantageous for agriculture. 
Information transparency is insufficient in agricultural logistics. As there are hardly any digital processes in this area, data can hardly be exchanged. However, this would be absolutely necessary to support the upstream and downstream processes.

Legal regulations are leading to an increasing contracting out of logistics services to agricultural contractors. Further forms of demand-oriented trading are not to be seen. Exchanges for the procurement of services and capacities have been tested, but have not yet become established.

In logistical processes, there are significant losses in efficiency due to a lack of transparency and the compulsory parallelism of sub-processes. As a result, waste leads to unnecessary consumption of resources and can thus be described as unsustainable. Transparency can improve this situation.

Process orientation is an outstanding goal in logistics, but it is only partially achieved for the reasons mentioned above. Process orientation and sustainability are mutually dependent.

The planning and control of logistical processes is almost exclusively experience-based. If it is possible to create additional knowledge and possibilities for action with methods of automated knowledge and learning, further potential can be raised. This will also benefit the documentation and analysis of processes, e.g., by automatically recognising defined states and providing recommendations for action in the next step.

So far, collaboration has mainly taken place through informal communication. The development of tools to improve transparency is one step that enables improved collaboration. Building on this, however, it is necessary to offer decision support with quantitative methods.

The networking of process participants in logistical processes is a basic prerequisite for creating transparency and improving processes. In contrast to industrial processes, permanent availability and sufficient bandwidth for the transmission of messages cannot be assumed. Therefore, it is important here to achieve the highest possible robustness in communication with the help of suitable technologies and methods.

Interoperability is the basic prerequisite for establishing networking in logistical processes. The standardisation of messages, such as in the context of ISOBUS, is one way. Self-describing interfaces, e.g., in the context of web services, enable further flexibility.

\subsection{Approaches for Industry 4.0 in Livestock Farming}

Animal husbandry in agriculture has many more parallels to industry than arable farming. Production takes place in buildings with regulated structures and a continuous process throughout the year. This suggests that there may already be more approaches to Industry 4.0 to be found here.

Automation is widespread in dairy farming due to the clearly structured and recurring daily processes. This has led to a large number of automated systems and sensors in dairy farming. The most important building blocks are the automatic milking system (AMS), the automatic feeding system (AFS), and automatic cleaning and bedding systems. In addition, a variety of sensors can be found in the barn, e.g., for animal identification, animal location, heat detection, calving detection, or barn climate [19-21]. The situation is similar in pig and poultry farming. Here, feeding, climate control, and manure removal are also automated.

In the area of digital individualisation, there are a wide variety of approaches in animal husbandry. One system that is already widely used for dairy cows and sows is the individualised distribution of concentrated feed via a station with identification of the animal via transponder. Another is the matching of cows in the AMS on the basis of the stored body measurements, among other things. However, it is apparent that many points of individualisation are not yet being used. For example, there is still no individual marketing of milk according to the protein pattern of the cow, and in the case of poultry and pigs, work is only done in groups and individuality is not taken into account. 
There are hardly any signs of flexibilisation in livestock farming. The trend is currently still towards standardisation as it corresponds to Industry 3.0. The potential for flexibility is not being used.

In terms of its basic structure, livestock farming is actually predestined for comprehensive information transparency. In the individual systems, the data are also collected and used accordingly. However, unfortunately, there is no general and open data interface to make the data sufficiently public and share it with other systems. In some cases, the necessary information transparency is not even given between different systems of one manufacturer.

The lack of demand orientation is currently a major problem in livestock farming in Germany. Production structures are relatively inflexible and therefore have difficulty adapting to changes in demand. The easiest application would still be in poultry farming due to the short production cycles, and correspondingly difficult in pigs and dairy cows due to the longer production cycles.

Due to its structure, farm animal husbandry is fundamentally process-oriented, with the main processes, such as meat, milk, or egg production, being linked to correspondingly complex secondary processes.

A common problem in livestock farming is that these processes are usually not documented in a structured way that is comprehensible to others. This means that measuring points and links are not optimally recognised, which makes the use of decision models and their implementation more difficult. Methods from the Industry 4.0 toolbox would offer fundamental approaches to improving process orientation here.

In the area of automated knowledge and learning, current automation in animal husbandry offers great potential, as animal-specific data series are continuously generated. However, these data are not yet consistently used in the sense of Industry 4.0. The situation is similar with collaboration skills. Here, the networking of various automatic systems in the barn would result in many approaches for Industry 4.0. For example, a measured change in the movement activity of fattening pigs could lead to an automatic adjustment of the climate control. This intelligent linking of different automated systems also enables an optimisation of productivity, which can simultaneously lead to a change in the farmer's work structure in the system.

In principle, livestock farming offers good conditions for networking the individual systems due to its fixed spatial structure. In many cases, networking can be done via cables to a central point. Difficulties are often encountered here in the recording of individual data concerning the animal using wireless networks, as there is no uniform data standard.

Areas such as piglet production, chick production, feed production, and manure spreading can be outsourced as animal husbandry services. However, it is often the case that, although the process or product is outsourced, no arrangements are made for data exchange or it does not take place. As a result, these areas are often underrepresented on the farm in terms of data and thus cannot be used for networked decisions.

\subsection{Challenges for the Implementation of Industry 4.0 Technologies and Concepts into Agriculture}

The challenges for the implementation of Industry 4.0 in agriculture can be identified as process orientation, standardisation, data communication, and knowledge transfer. The point of process orientation results from the difficulties in agriculture to clearly delineate and determine individual processes. The small-scale networking in agriculture is significantly greater than in industry, which makes it difficult to adopt process orientation. The points of standardisation and data communication are mutually dependent. They appear in many areas and make the necessary data exchange between the individual systems more difficult. The area of knowledge transfer is based on the points of automated knowledge and learning and collaboration competence and includes both knowledge management between the individual processes and knowledge transfer to the users. 


\section{Discussion}

When analysing the application state of Industry 4.0 technologies and implementation options in agriculture, it is noticeable that although many things initially look like 4.0, on closer inspection, decisive aspects, such as cross-sector networking or the individualisation and flexibilisation of production, are missing. Non-networked digital solutions are therefore more likely to be classified as automated stand-alone solutions of Industry 3.0. The challenges for the implementation of Industry 4.0 in agriculture can be identified as process orientation, standardisation, data communication, and knowledge transfer. In the case of process orientation, it can be seen that this has not yet fully penetrated agriculture and tools such as digital twins cannot be sufficiently implemented. This is also reflected in standardisation. Here, the ISOBUS is available in arable farming, but adapted development is also necessary here. Unfortunately, a similar system is lacking in livestock farming. The individual systems are mostly self-contained and do not communicate and cooperate with each other. In addition, the transitions between the individual links in the production chain are not standardised across the board. Here, even in the case of in-house management systems, a step back to the paper level is taken.

In addition to the organisational structure of data exchange, the technical infrastructure must also be expanded accordingly, as both wired and radio-based data networks still have performance gaps, especially in rural areas. In order to be able to understand and appropriately use the possibilities of Industry 4.0 applications, a corresponding structure for the further training of users is also necessary. New and flexible learning structures that adapt to the requirements of the users are also necessary here.

A comparison of the results with the literature shows that the literature usually only looks at individual points of Industry 4.0 and agriculture. These are mostly technical aspects. Individual methods used in connection with Industry 4.0 are applied to agriculture. This approach ranges from general technology systems such as IoT [22] to special techniques such as wire networks [23] to detail issues of soil testing devices [24].

Less frequently, the structural aspects of Industry 4.0 and agriculture such as knowledge management [25] are considered. In all these considerations, only partial aspects of the possible changes emerge. This makes it clear that Industry 4.0 in agriculture must always be considered as a whole system. This joint consideration of technical and structural aspects of agriculture in connection with Industry 4.0 [26] also shows similar results to this study.

Another aspect that stands out in the analysis of Industry 4.0 in agriculture is the gap between the practical implementation and the technologically possible realisation. An example of this is tractor implement management (TIM) for balers and tractors. Here, implementation is slow, although it would be technically possible. With a view to Industry 4.0 approaches, there are also other possible aspects, such as track shifting via process steps, track planning based on the combine harvester's performance, or logistics planning based on yield estimates. This can also be observed in livestock farming. Here, quarter-individual milking based on past milking cycles or the route optimisation of cleaning robots based on the current movement data of cows would correspond to the basic idea of Industry 4.0.

In many cases, these technological developments would only require corresponding adjustments and coordination. However, this requires the will of a cross-manufacturer, which is often hindered by company-specific interests. It is obvious that without crossmanufacturer networking, no application of Industry 4.0 in agriculture is possible, but only the automation of individual machines.

Author Contributions: Conceptualization, methodology and investigation, H.B., R.B., E.C., J.H., M.K., J.M., M.K., J.M., T.S., H.T., C.W. (Cornelia Weltzien), and C.W. (Clemens Westerkamp); data curation, M.B. and A.H.; writing-original draft preparation, H.B.; writing-review and editing, R.B., M.K., J.M. T.S., and H.T.; project administration, M.B., and A.H. All authors have read and agreed to the published version of the manuscript. 
Funding: The administrative costs of the project are funded by the German Federal Ministry of Food and Agriculture (BMEL) based on a resolution of the German Bundestag. The project (Networking and transfer project for digitization in agriculture (DigiLand)) is carried out by the Federal Agency for Agriculture and Food (BLE) within the framework of the Innovation Support Program.

Institutional Review Board Statement: Not applicable.

Informed Consent Statement: Not applicable.

Acknowledgments: Many thanks to the colleagues from industry and agriculture for the discussions on the topic of Industry 4.0 .

Conflicts of Interest: The authors declare no conflict of interest.

\section{References}

1. Ghobakhloo, M. Industry 4.0, digitization, and opportunities for sustainability. J. Clean. Prod. 2020, 252, 119869. [CrossRef]

2. Schmidt, C. Landwirtschaft 4.0-Digitalisierung als Chance für eine nachhaltige Landwirtschaft. In Digitalisierung im Spannungsfeld von Politik, Wirtschaft, Wissenschaft und Recht; Bär, C., Grädler, T., Mayr, R., Eds.; Springer: Berlin/Heidelberg, Germany, 2018. [CrossRef]

3. Rose, D.C.; Chilvers, J. Agriculture 4.0: Broadening Responsible Innovation in an Era of Smart Farming. Front. Sustain. Food Syst. 2018, 2, 87. [CrossRef]

4. Ozdogan, B.; Gacar, A.; Aktas, H. Digital Agriculture Practices in the Context of Agriculture 4.0. J. Econ. Financ. Account. 2017, 4, 186-193. [CrossRef]

5. Weltzien, C. Digital agriculture-Or why agriculture 4.0 still offers only modest returns. Landtechnik 2016, 71, 66-68. [CrossRef]

6. Rojko, A. Industry 4.0 Concept: Background and Overview. Int. J. Interact. Mob. Technol. 2017, 11, 77-90. [CrossRef]

7. Fraser, E.D.G.; Campbell, M. Agriculture 5.0: Reconciling Production with Planetary Health. One Earth 2019, 1, 278-280. [CrossRef]

8. Aulbur, W.; Henske, R.; Morris, G.; Schelfi, G. Farming 4.0: How precision agriculture might save the world. In Roland Berger Focus; Roland Berger GmbH: München, Germany, 2019.

9. Murugesan, R.; Sudarsanam, S.K.; Malathi, G.; Vijayakumar, V.; Neelanarayanan, V.; Venugopal, R.; Rekha, D.; Saha, S.; Bajaj, R.; Miral, A.; et al. Artificial Intelligence and Agriculture 5.0. Int. J. Recent Technol. Eng. 2019, 8, 1870-1877.

10. Kagermann, H.; Lukas, W.D.; Wahlster, W. Industrie 4.0: Mit dem Internet der Dinge auf dem Weg zur 4. industriellen Revolution. VDI Nachr. 2011, 13, 2.

11. Müller, J.; Dotzauer, V.; Voigt, K. Industry 4.0 and its Impact on Reshoring Decisions of German Manufacturing Enterprises. In Supply Management Research. Advanced Studies in Supply Management; Bode, C., Bogaschewsky, R., Eßig, M., Lasch, R., Stölzle, W., Eds.; Springer Gabler: Wiesbaden, Germany, 2017. [CrossRef]

12. Vaidya, S.; Ambad, P.; Bhosle, S. Industry 4.0—A Glimpse. Procedia Manuf. 2018, 20, 233-238. [CrossRef]

13. Frank, A.G.; Dalenogare, L.S.; Ayala, N.F. Industry 4.0 technologies: Implementation patterns in manufacturing companies. Int. J. Prod. Econ. 2019, 210, 15-26. [CrossRef]

14. Xu, L.D.; Xu, E.L.; Li, L. Industry 4.0: State of the art and future trends. Int. J. Prod. Res. 2018, 56, 2941-2962. [CrossRef]

15. Bauernhansl, T. Die Vierte Industrielle Revolution-Der Weg in ein wertschaffendes Produktionsparadigma. In Handbuch Industrie 4.0; Springer Vieweg: Berlin, Germany, 2017; Volume 4, pp. 1-31. [CrossRef]

16. Demont, A.; Paulus-Rohmer, D. Developing Industry 4.0 business models systematically. In Digital Transformation of Business Models; Daniel, S., Andreas, R., Johanna, A., Thomas, W., Michael, J., Eds.; Springer Trade Media: Wiesbaden, Germany, 2017; Volume 3, pp. 97-125.

17. Bauernhansl, T.; Schatz, A. Industry 4.0 for business model innovations. Procedure for developing industry-specific business model scenarios. Wt Werkstattstech. Online 2015, 105, 79-83. [CrossRef]

18. Sonnen, J. Digitization and Automation Digitization and networking. In Yearbook Agricultural Engineering 2018; Frerichs, L., Ed.; Institut für mobile Maschinen und Nutzfahrzeuge: Braunschweig, Germany, 2019; pp. 1-11. [CrossRef]

19. Höhendinger, M.; Schlereth, N.; Treiber, M.; Höld, M.; Stumpenhausen, J.; Bernhardt, H. Potential of cyber-physical systems in German dairy farming. In Proceedings of the 2019 ASABE Annual International Meeting, Boston, MA, USA, 7-10 July 2019. [CrossRef]

20. Bernhardt, H. Livestock Engineering Machinery and Techniques for Cattle Husbandry. In Yearbook Agricultural Engineering 2018; Frerichs, L., Ed.; Institut für mobile Maschinen und Nutzfahrzeuge: Braunschweig, Germany, 2019; pp. 1-13. [CrossRef]

21. Bernhardt, H.; Höhendinger, M.; Gräff, A.; Hijazi, O.; Höld, M.; Reger, M.; Stumpenhausen, J. Development of Automatic Milking in Germany. In Proceedings of the 2019 ASABE Annual International Meeting, Boston, MA, USA, 7-10 July 2019. [CrossRef]

22. Raj, M.; Gupta, S.; Chamola, V.; Elhence, A.; Garg, T.; Atiquzzaman, M.; Niyato, D. A survey on the role of Internet of Things for adopting and promoting Agriculture 4.0. J. Netw. Comput. Appl. 2021, 187, 103107. [CrossRef]

23. Khujamatov, K.E.; Toshtemirov, T.K. Wireless sensor networks based Agriculture 4.0: Challenges and apportions. In Proceedings of the 2020 International Conference on Information Science and Communications Technologies (ICISCT), Tashkent, Uzbekistan, 3-4 November 2020; pp. 1-5. [CrossRef] 
24. Lukowska, A.; Tomaszuk, P.; Dzierżek, K.; Magnuszewski, L. Soil sampling mobile platform for Agriculture 4.0. In Proceedings of the 2019 20th International Carpathian Control Conference (ICCC), Kraków-Wieliczka, Poland, 26-29 May 2019; pp. 1-4. [CrossRef]

25. Pogorelskaia, I.; Várallyai, L. Agriculture 4.0 and the role of education. J. Agric. Inform. 2020, 11, 45-51. [CrossRef]

26. Liu, Y.; Ma, X.; Shu, L.; Hancke, G.; Abu-Mahfouz, A. From Industry 4.0 to Agriculture 4.0: Current Status, Enabling Technologies, and Research Challenges. IEEE Trans. Ind. Inform. 2021, 17, 4322-4334. [CrossRef] 